\title{
Review \\ Hypoxia \\ HIF-mediated articular chondrocyte function: prospects for cartilage repair
}

\author{
Christopher L Murphy, Brendan L Thoms, Rasilaben J Vaghjiani and Jérôme E Lafont
}

The Kennedy Institute of Rheumatology, Faculty of Medicine, Imperial College London, 65 Aspenlea Road, London W6 8LH, England

Corresponding author: Christopher L Murphy, c.murphy@imperial.ac.uk

Published: 5 February 2009

This article is online at http://arthritis-research.com/content/11/1/213

(c) 2009 BioMed Central Ltd
Arthritis Research \& Therapy 2009, 11:213 (doi:10.1186/ar2574)

matrix components [11-13], and through the inhibition of angiogenesis [14]. In addition to mediating the ubiquitous hypoxia responses, hypoxia-inducible factors (HIFs) also appear to be critical to these tissue-specific responses in chondrocytes.

\section{Hypoxia-inducible factors}

In the mid-1990s a major breakthrough was made in our understanding of the molecular mechanisms mediating cellular responses to hypoxia with the discovery of HIF-1 [15]. The stability and function of HIF is regulated post-translationally by hydroxylation of specific amino acid residues. In the presence of sufficient molecular oxygen, HIF is degraded almost as soon as it is made due to hydroxylation of specific proline residues that target the HIF- $\alpha$ subunit for Von HippelLindau tumour suppressor protein (pVHL)-mediated proteosomal degradation. Conversely, when oxygen levels are limiting (typically $<5 \%$ ), hydroxylation is inhibited and HIF- $\alpha$ escapes degradation, and is free to heterodimerise with the constitutively expressed HIF- $\beta$ subunit (also called Aryl hydrocarbon nuclear translocator (ARNT)). This complex translocates to the nucleus, binding specific consensus sequences (-RCGTG-) within the promoter of its target genes and thus activating their transcription (Figure 1).

Other HIF- $\alpha$ members were subsequently discovered, namely HIF- $2 \alpha$, which is structurally similar to HIF- $1 \alpha$, and more recently HIF- $3 \alpha$. The latter was shown to produce at least six different isoforms following alternative splicing [16]. HIF-1 $\alpha$ and HIF- $2 \alpha$ have the same fundamental protein structure, a basic-helix-loop-helix (bHLH) domain at the amino terminus, an intermediate PER-ARNT-SIM (PAS) domain, and a transactivation domain (TAD). HIF3- $\alpha$ lacks the last of these, and it has been suggested that it could act as a dominant negative for HIF- $1 \alpha$ and HIF-2 $\alpha[16,17]$.

$\mathrm{DMOG}=$ dimethyloxaloylglycine; FIH = Factor inhibiting HIF; HAC = human articular chondrocyte; HIF = hypoxia-inducible factor; $\mathrm{MSC}=$ mesenchymal stem cell; PHD = prolyl hydroxylase domain; $\mathrm{pVHL}=$ Von Hippel-Lindau tumour suppressor protein. 


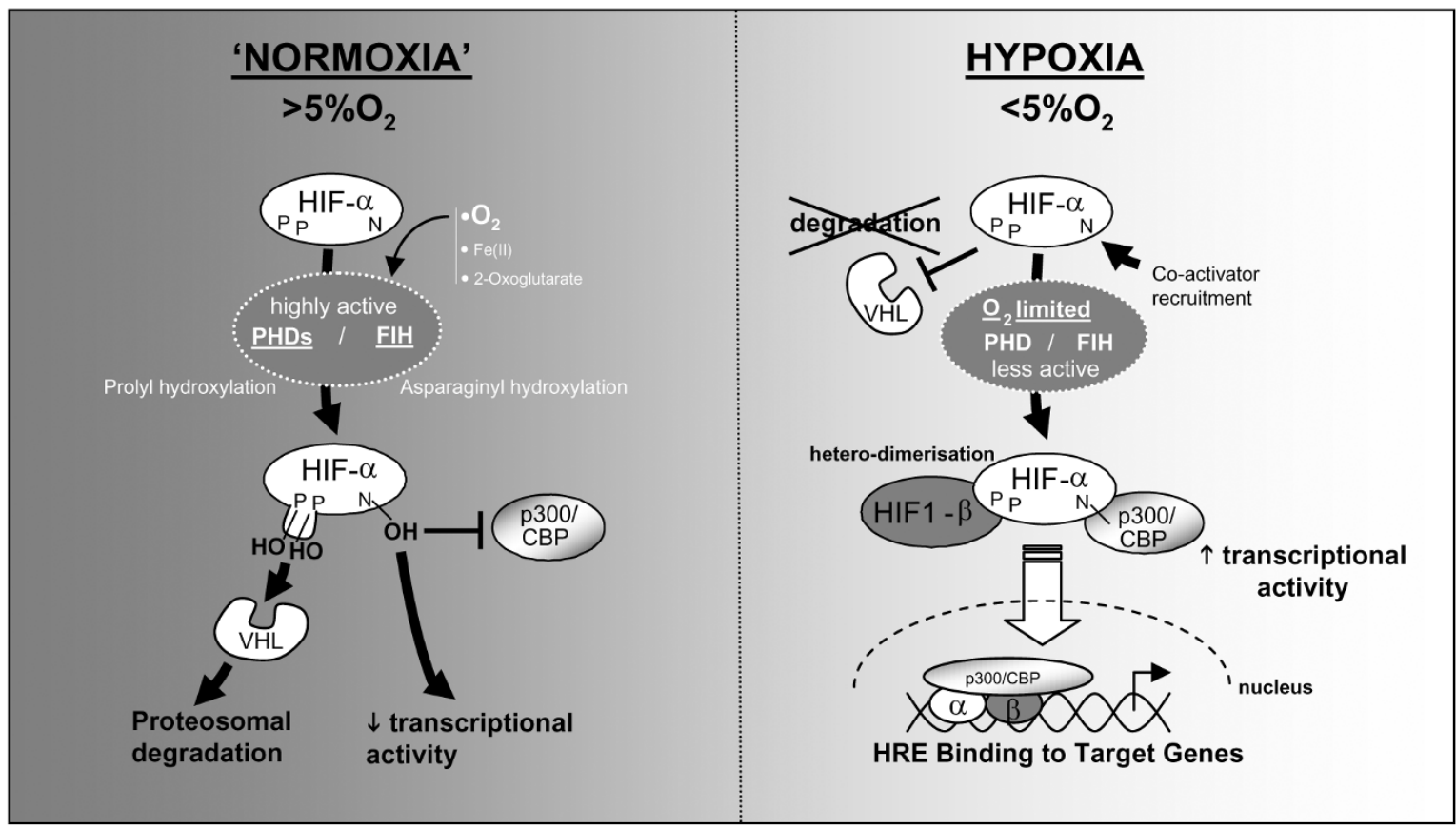

Hypoxia-inducible factor (HIF) function. HIFs are transcription factors regulated post-transcriptionally by oxygen levels in the cell through hydroxylation on specific proline and asparaginyl amino acid residues. These HIF-specific hydroxylases are the direct oxygen sensors as they use molecular oxygen (in addition to iron and oxoglutarate) to function. Prolyl hydroxylase domain (PHD) enzymes hydroxylate specific proline residues, which target the HIF- $\alpha$ subunit for Von Hippel-Lindau tumour suppressor protein (VHL)-mediated proteosomal degradation. In addition, Factor inhibiting HIF (FIH) hydroxylates a specific asparaginyl residue, which prevents recruitment of co-activator p300/CBP, and thus decreases HIF's transcriptional activity. When oxygen levels are limiting (that is, in hypoxia), these hydroxylases are inhibited, and hence HIF- $\alpha$ escapes degradation, and can heterodimerise with HIF-1 $\beta$ and migrate to the nucleus to activate transcription of target genes through binding to their hypoxia response elements (HREs).

\section{HIFs in developing cartilage}

Data have emerged in recent years highlighting the importance of HIF- $1 \alpha$ in the developing growth plate in the mouse [18]. Schipani and colleagues [4] first demonstrated that the developmental growth plate was hypoxic, and deletion of HIF$1 \alpha$ led to chondrocyte death coupled with decreased expression of the CDK inhibitor p57, thus strongly suggesting that HIF-1 $\alpha$ is essential for chondrocyte survival and growth arrest. More recent data have highlighted HIF- $1 \alpha$ 's role in regulation of differentiation of the limb bud mesenchyme and in joint development [18]. Hypoxia was also shown to increase matrix synthesis of isolated epiphyseal chondrocytes in a HIF-1 $\alpha$-dependent manner [19]. HIF-2 $\alpha$ was shown to be elevated during chondrocyte differentiation and to be present in the articular cartilage in a study by Stewart and colleagues [20]. Deletion of VHL (which results in overexpression of HIF$1 \alpha$ and HIF-2 $\alpha$ ) increases matrix deposition by chondrocytes during growth plate development [21]. The role of HIFs in the permanent articular cartilage has been little studied. However, a recent study has reported induction of osteoarthritis in $\mathrm{BALB} / \mathrm{c}$ mice after intra-articular injection of the anti-angiogenic compound 2-methoxyoestradiol [22]. Although promising, 2-methoxyoestradiol is not a specific HIF-targeting compound and its mechanism of action is not clear, although it is thought to be related to disruption of microtubule assembly in the cell [23]. In addition, HIF-2 $\alpha$ was not investigated in this study, but presumably was also affected by 2-methoxyoestradiol treatment in a manner similar to HIF- $1 \alpha$.

Despite the above-mentioned important findings in the mouse, extending these data to humans is fraught with difficulties. A major concern with regard to hypoxia is the different thickness between human and mouse cartilage. For example, being merely a few cells in thickness, appreciable oxygen diffusion is possible in mouse knee articular cartilage; whereas the equivalent site in humans is several millimetres thick. As a consequence, the oxygen concentration in human articular cartilage may be significantly lower than that in the mouse [710,24]. In addition, the mechanical loads experienced by mouse and human knees are obviously hugely different [25]. Hence, although extremely useful for developmental studies, for the understanding of adult articular cartilage in humans, the mouse model is limited.

\section{Role of HIFs in hypoxic induction of the human articular chondrocyte phenotype}

It has long been known that the chondrocyte phenotype is unstable in culture [26-28]. Moreover, chondrocyte pheno- 


\section{Mesenchymal Stem Cells}



Hypoxia enhances chondrogenic differentiation of mesenchymal stem cells (MSCs). Clonally derived MSCs were isolated from the bone marrow of 5 -week-old mice. After 1 week in chondrogenic medium (containing $5 \mathrm{ng} / \mathrm{ml}$ transforming growth factor- $\beta 3$ ) at different oxygen concentrations, cultures were stained for cartilage-specific type II collagen. Enhanced collagen II staining was observed in cultures exposed to reduced oxygen concentrations.

typic alterations are observed in cartilage pathology, such as osteoarthritis [29]. Controlling the chondrocyte phenotype remains, therefore, a major challenge for cartilage repair strategies. Being the only cell type within the tissue, the chondrocytes are solely responsible for secreting the specialised extracellular matrix that gives the tissue its biomechanical function. Articular cartilage is under two permanent stresses, mechanical and hypoxic. Although it is widely accepted that loading and compression applied to cartilage are potent regulators of chondrocyte physiology [30-33], the role of hypoxia on chondrocyte function is less well established. A general response of articular chondrocytes to their hypoxic environment is their reliance on anaerobic metabolism to generate cellular energy (ATP), and oxygen consumption of the tissue is accordingly low [34]. In addition, hypoxia has specifically been shown to promote tissue function by upregulating expression of cartilage matrix genes in isolated bovine $[13,35]$ and human articular chondrocytes (HACs) [36]. Similar results have been reported for human meniscal cells [37]. Applying the technique of RNA interference, we subsequently demonstrated that HIF- $2 \alpha$, but not HIF- $1 \alpha$, was critical for this hypoxic induction of cartilage matrix synthesis in HACs [11]. Furthermore, the main matrix genes, such as those encoding Col-2a1, aggrecan and Col-9, are not direct HIF targets, but are upregulated by hypoxia through cartilagespecific transcription factor SOX9. Whether HIF-2 $\alpha$ directly targets SOX9 in HACs remains unknown. However, mouse stromal cells (ST2) transfected with a Sox9 promoter construct showed upregulation under hypoxia [38], and when putative hypoxia response element sequences (located within 
(a)

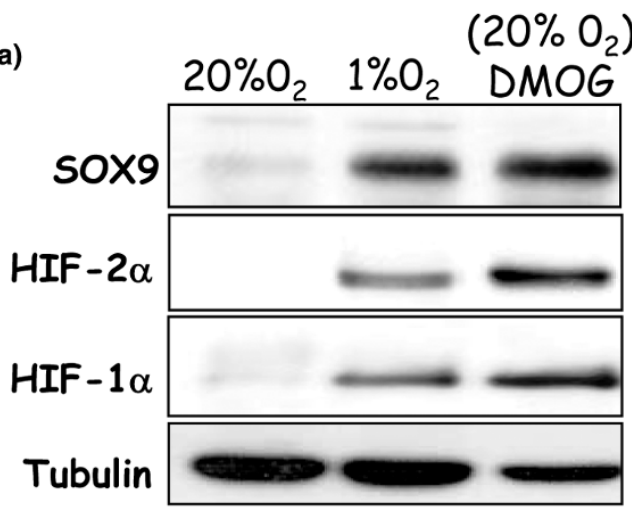

(b)

\begin{tabular}{|c|c|c|c|c|c|}
\hline $20 \% \mathrm{O}_{2}$ & \multicolumn{4}{|c|}{ DMOG (in $\left.20 \% 0_{2}\right)$} & \\
\hline Luc & HIF1 & HIF2 & $1+2$ & Luc & \\
\hline & Es & $\sqrt{2}$ & $=$ & & \\
\hline
\end{tabular}

(c)



Hydroxylase inhibition, like hypoxia, upregulates SOX9 in human articular chondrocytes by an HIF-2 $\alpha$ dependent mechanism. (a) The non-specific hydroxylase inhibitor dimethyloxaloylglycine (DMOG) upregulates hypoxia-inducible factor (HIF)-1 $\alpha, \mathrm{HIF}-2 \alpha$, and SOX9 transcription factors in human articular chondrocytes. (b) Like hypoxia, DMOG induction of SOX9 in human articular chondrocytes is HIF-2 $\alpha$, but not HIF-1 $\alpha$, dependent. Luc, luciferase; siRNA, small interfering RNA. (c) Relative mRNA levels of HIF-targeting prolyl hydroxylase domain (PHD) enzymes in human articular chondrocytes (from $n=7$ patients) exposed to both hypoxia and normoxia. ${ }^{\star \star \star} P<0.001$. Error bars indicate standard deviation about the mean.

the first $500 \mathrm{bp}$ ) were mutated, hypoxic induction was abolished. These results have been supported more recently in micromass culture experiments, which showed, using chromatin immunoprecipitation, recruitment of HIF- $1 \alpha$ to the Sox 9 promoter precisely on the same hypoxia response element-containing site [39].

\section{Hypoxia, HIFs and mesenchymal stem cells for cartilage repair}

The ability of mesenchymal stem cells (MSCs) to differentiate into chondrocytes (in vitro and in vivo) and to be readily expanded in tissue culture without loss of multilineage potential has made them very attractive candidates for cell-based articular cartilage repair. In addition, unlike articular chondrocytes, the use of MSCs is not hindered by the availability of suitable healthy tissue since MSCs can be isolated from a variety of tissues [40-42]. Implantation of MSCs in an animal model of osteoarthritis has resulted in engraftment of the cells in the meniscus, fat pad, and synovium, with regeneration of the medial meniscus [43]. In addition, degeneration of the articular cartilage and osteophytic remodelling were reduced in MSC implanted joints compared with control joints. Similar results have been reported in the treatment for focal defects in articular cartilage [44]. In a clinical trial MSCs were transplanted using hydroxyapatite ceramic scaffolds to treat severe osteochondral damage after septic arthritis of the knee [45]. Successful cartilage-like tissue regeneration was observed by a second athroscopy.

Recent studies have reported that hypoxia enhances chondrogenic differentiation of MSCs (in comparison to control cultures at ambient oxygen tension) $[38,46]$. In addition, Lennon and colleagues have also reported that low oxygen enhanced in vivo chondrogenesis of rat MSCs [47]. Our laboratory investigated the effects of oxygen tension $\left(20 \%, 5 \%\right.$, and $\left.1 \% \mathrm{O}_{2}\right)$ on the chondrogenic differentiation of both murine and human MSCs when cultured in the presence of $5 \mathrm{ng} / \mathrm{ml}$ transforming growth factor- $\beta 3$. Chondrogenic 


\section{HYPOXIA}



Hypoxia-inducible factor (HIF)-2 $\alpha$-mediated induction of cartilage matrix synthesis by human articular chondrocytes (HACs) may be possible through the inhibition of specific HIF-2 $\alpha$ targeting prolyl hydroxylase domain (PHD) enzymes.

differentiation took 3 to 4 days in reduced oxygen tensions, and 1 week in cultures exposed to $20 \%$ oxygen. Furthermore, low oxygen tension significantly enhanced the number of chondrogenic nodules formed, as well as the intensity of cartilage-specific type II collagen staining, in comparison to $20 \%$ cultures (Figure 2). Interestingly, when cultures were exposed to reduced transforming growth factor- $\beta 3$ levels $(1 \mathrm{ng} / \mathrm{ml})$, chondrogenic nodules formed in only $5 \%$ and $1 \%$ $\mathrm{O}_{2}$ (that is, not 20\%; unpublished data), suggesting hypoxia plays an essential role in the onset of chondrocyte differentiation from MSCs. However, a fundamental problem with the use of MSCs for cartilage repair is that they readily become terminally differentiated, with production of type $\mathrm{X}$ collagen [48]. Obviously, for the permanent articular cartilage this is undesirable. Since type $\mathrm{X}$ collagen production occurs with a concomitant decrease in SOX9 expression in joint development [49], it is tempting to speculate that hypoxia may delay or inhibit terminal differentiation of MSCs through induction and maintenance of SOX9 levels.

The specific role of HIFs in this hypoxic induction of chondrogenesis from MSCs deserves further exploration and, interestingly, Hardingham and colleagues [50] have recently shown that human MSCs isolated from the infrapatellar fat pad showed enhanced chondrogenic differentiation in hypoxia and, furthermore, that HIF- $2 \alpha$, but not HIF- $1 \alpha$, was upregulated in these cultures. This supports findings in our laboratory that specifically HIF- $2 \alpha$ promotes the differentiated HAC phenotype [11].

\section{HIF-targeting hydroxylases: the direct oxygen sensors}

The direct oxygen sensors are not the HIFs, but the hydroxylases targeting them since the latter are enzymes that require oxygen as a co-factor. Hydroxylation of HIF proline residues occurs on the amino-terminal end of the transactivation domain (on Pro402 and Pro564 of human HIF-1 $\alpha$ ) [51]. Three prolyl hydroxylases, prolyl hydroxylase domain enzymes 1 to 3 (PHD-1 to PHD-3) have been shown to act in this way [52]. An asparaginyl residue located in the carboxyterminal domain (on Asn803 of human $\mathrm{HIF}-1 \alpha$ ) is also hydroxylated by a specific enzyme called Factor inhibiting HIF (FIH). Hydroxylation by $\mathrm{FIH}$ inhibits transcriptional activity of HIF by preventing recruitment of the transcriptional coactivator p300/CBP [53,54].

The HIF targeting hydroxylases (PHD1/2/3 and FIH) belong to a family of iron- and oxoglutarate-dependent hydroxylases, and dimethyloxaloylglycine (DMOG; being an analogue of oxoglutarate) can inhibit all family members. We have shown that DMOG, like hypoxia, stabilises HIF- $1 \alpha$ and HIF- $2 \alpha$ in human articular chondrocytes, and subsequently induces SOX9 in a specifically HIF-2 $\alpha$-dependent manner (Figure 3a,b). Although a useful experimental tool, DMOG is not appropriate for therapeutic application since, being a non-specific hydroxylase inhibitor, it also inhibits procollagen hydroxylases such as prolyl and lysyl hydroxylases, which are critical for post-transcriptional processing and triple helical formation of cartilage collagens [55]. In fact, these collagen prolyl hydroxy- 
lases are themselves upregulated by hypoxia [56], and we have observed similar hypoxic induction of lylsyl hydroxylase (PLOD2) in human articular chondrocytes [12]. Interestingly, Gelse and colleagues [22] have recently reported that DMOG injection into murine joints led to increased intracellular accumulation of collagen molecules, presumably due to defective collagen processing and hence impaired secretion. Thus, there is a critical need for development of HIFspecific hydroxylase inhibitors if these deleterious effects on collagen processing are to be avoided.

All three HIF-targeting prolyl hydroxylases (PHD1/2/3) have been detected in the maturing zone of the mouse growth plate [57]. PHD2 was shown by Pouyssegur and colleagues to be dominant hydroxylase regulating HIF-1 $\alpha$ [58], at least in non-chondrocytic cell lines. Such PHD selectivity for HIF-1 $\alpha$ has also been shown by Applehoff and co-workers [52]. Since HIF- $2 \alpha$ and not HIF- $1 \alpha$ is involved in the control of the human chondrocyte phenotype [11], it is now important to uncover if PHDs show selectivity for HIF-2 $\alpha$ in human articular chondrocytes. Interestingly, in recent microarray experiments on HACs, we have observed a very pronounced hypoxic induction of PHD3 mRNA [12], although PHD2 message was the most abundant both in hypoxia and normoxia (Figure 3c). Nevertheless, the relative contribution of each hydroxylase may be dependent on the prevailing oxygen tension.

\section{Concluding remarks}

As a permanent stress, hypoxia influences general chondrocyte metabolism, and most importantly tissue-specific production of cartilage matrix proteins. This raises the exciting possibility of manipulating hypoxia-induced pathways to promote cartilage synthesis and to stimulate repair. Thus, manipulating potentially HIF- $2 \alpha$ specific PHDs in cartilage could lead to enhanced chondrocyte function without perturbing the HIF system in other tissues, or indeed even the HIF- $1 \alpha$ levels within the tissue itself (Figure 4). Since HIF-1 $\alpha$ overexpression may promote the angiogenic phenotype favouring tumourigenesis [59], in addition to induction of catabolic cytokines [60], such isoform- and tissue-specific HIF manipulation is obviously highly desirable. Key to the therapeutic application of such research will be the development of isoform-specific PHD small molecule inhibitors.

$$
\begin{gathered}
\text { This review is part of a series on } \\
\text { Hypoxia } \\
\text { edited by Ewa Paleolog. }
\end{gathered}
$$

Other articles in this series can be found at http://arthritis-research.com/articles/ review-series.asp?series=ar_hypoxia

\section{Competing interests}

The authors declare that they have no competing interests.

\section{Acknowledgements}

CLM, BLT and RJV are supported by Arthritis Research Campaign, UK; JEL by the Biotechnology and Biological Sciences Research Council, UK, and by Arthritis Research Campaign, UK.

\section{References}

1. Mitchell P: Coupling of phosphorylation to electron and hydrogen transfer by a chemi-osmotic type of mechanism. Nature 1961, 191:144-148.

2. Semenza GL: Regulation of hypoxia-induced angiogenesis: a chaperone escorts VEGF to the dance. J Clin Invest 2001, 108: 39-40.

3. Gendron A, Kouassi E, Nuara S, Cossette C, D'Angelo G, Geadah D, du Souich P, Teitelbaum J: Transient middle cerebral artery occlusion influence on systemic oxygen homeostasis and erythropoiesis in Wistar rats. Stroke 2004, 35:1979-1984.

4. Schipani E, Ryan HE, Didrickson S, Kobayashi T, Knight M, Johnson RS: Hypoxia in cartilage: HIF-1alpha is essential for chondrocyte growth arrest and survival. Genes Dev 2001, 15: 2865-2876.

5. Goshima J, Goldberg VM, Caplan Al: The origin of bone formed in composite grafts of porous calcium phosphate ceramic loaded with marrow cells. Clin Orthop Relat Res 1991, 269: 274-283.

6. Pechak DG, Kujawa MJ, Caplan Al: Morphology of bone development and bone remodeling in embryonic chick limbs. Bone 1986, 7:459-472.

7. Brighton CT, Heppenstall RB: Oxygen tension in zones of the epiphyseal plate, the metaphysis and diaphysis. An in vitro and in vivo study in rats and rabbits. $J$ Bone Joint Surg Am 1971, 53:719-728.

8. Lund-Olesen K: Oxygen tension in synovial fluids. Arthritis Rheum 1970, 13:769-776.

9. Silver IA: Measurement of $\mathrm{pH}$ and ionic composition of pericellular sites. Philos Trans $R$ Soc Lond B Biol Sci 1975, 271: 261-272.

10. Treuhaft PS, DJ MC: Synovial fluid $\mathrm{pH}$, lactate, oxygen and carbon dioxide partial pressure in various joint diseases. Arthritis Rheum 1971, 14:475-484.

11. Lafont JE, Talma S, Murphy CL: Hypoxia-inducible factor 2alpha is essential for hypoxic induction of the human articular chondrocyte phenotype. Arthritis Rheum 2007, 56:3297-3306.

12. Lafont JE, Talma S, Hopfgarten C, Murphy CL: Hypoxia promotes the differentiated human articular chondrocyte phenotype through SOX9-dependent and -independent pathways. J Biol Chem 2008, 283:4778-4786.

13. Domm C, Schunke M, Christesen K, Kurz B: Redifferentiation of dedifferentiated bovine articular chondrocytes in alginate culture under low oxygen tension. Osteoarthritis Cartilage 2002, 10:13-22.

14. Bargahi A, Rabbani-Chadegani A: Angiogenic inhibitor protein fractions derived from shark cartilage. Biosci Rep 2008, 28:1521.

15. Wang GL, Jiang BH, Rue EA, Semenza GL: Hypoxia-inducible factor 1 is a basic-helix-loop-helix-PAS heterodimer regulated by cellular 02 tension. Proc Natl Acad Sci USA 1995, 92:55105514.

16. Maynard MA, Qi H, Chung J, Lee EH, Kondo Y, Hara S, Conaway $\mathrm{RC}$, Conaway JW, Ohh M: Multiple splice variants of the human HIF-3 alpha locus are targets of the von Hippel-Lindau E3 ubiquitin ligase complex. J Biol Chem 2003, 278:1103211040.

17. Hara S, Hamada J, Kobayashi C, Kondo Y, Imura N: Expression and characterization of hypoxia-inducible factor (HIF)-3alpha in human kidney: suppression of HIF-mediated gene expression by HIF-3alpha. Biochem Biophys Res Commun 2001, 287: 808-813.

18. Provot S, Schipani E: Fetal growth plate: a developmental model of cellular adaptation to hypoxia. Ann NYAcad Sci 2007, 1117:26-39.

19. Pfander D, Cramer T, Schipani E, Johnson RS: HIF-1alpha controls extracellular matrix synthesis by epiphyseal chondrocytes. J Cell Sci 2003, 116:1819-1826. 
20. Stewart AJ, Houston B, Farquharson C: Elevated expression of hypoxia inducible factor-2alpha in terminally differentiating growth plate chondrocytes. J Cell Physio/ 2006, 206:435-440.

21. Pfander D, Kobayashi T, Knight MC, Zelzer E, Chan DA, Olsen BR, Giaccia AJ, Johnson RS, Haase VH, Schipani E: Deletion of Vhlh in chondrocytes reduces cell proliferation and increases matrix deposition during growth plate development. Development 2004, 131:2497-2508.

22. Gelse K, Pfander D, Obier S, Knaup KX, Wiesener M, Hennig FF, Swoboda B: The role of HIF-1alpha for the integrity of articular cartilage in murine knee joints. Arthritis Res Ther 2008, 10: R111.

23. Mabjeesh NJ, Escuin D, LaVallee TM, Pribluda VS, Swartz GM, Johnson MS, Willard MT, Zhong H, Simons JW, Giannakakou P: 2ME2 inhibits tumor growth and angiogenesis by disrupting microtubules and dysregulating HIF. Cancer Cell 2003, 3:363375.

24. Falchuk KH, Goetzl EJ, Kulka JP: Respiratory gases of synovial fluids. An approach to synovial tissue circulatory-metabolic imbalance in rheumatoid arthritis. Am J Med 1970, 49:223-231.

25. Adams MA: The mechanical environment of chondrocytes in articular cartilage. Biorheology 2006, 43:537-545.

26. Glowacki J, Trepman E, Folkman J: Cell shape and phenotypic expression in chondrocytes. Proc Soc Exp Biol Med 1983, 172: 93-98.

27. von der Mark K, Gauss V, von der Mark H, Muller P: Relationship between cell shape and type of collagen synthesised as chondrocytes lose their cartilage phenotype in culture. Nature 1977, 267:531-532.

28. Watt FM: Effect of seeding density on stability of the differentiated phenotype of pig articular chondrocytes in culture. $J$ Cell Sci 1988, 89:373-378.

29. Aigner T, Fundel K, Saas J, Gebhard PM, Haag J, Weiss T, Zien A Obermayr F, Zimmer R, Bartnik E: Large-scale gene expression profiling reveals major pathogenetic pathways of cartilage degeneration in osteoarthritis. Arthritis Rheum 2006, 54:35333544

30. Urban JP: The chondrocyte: a cell under pressure. $\mathrm{Br} J$ Rheumatol 1994, 33:901-908.

31. Lane Smith R, Trindade MC, Ikenoue T, Mohtai M, Das P, Carter DR, Goodman SB, Schurman DJ: Effects of shear stress on articular chondrocyte metabolism. Biorheology 2000, 37:95-107.

32. Smith RL, Carter DR, Schurman DJ: Pressure and shear differentially alter human articular chondrocyte metabolism: a review. Clin Orthop Relat Res 2004, 427(Suppl):S89-95.

33. Monfort J, Garcia-Giralt N, Lopez-Armada MJ, Monllau JC, Bonilla A, Benito P, Blanco FJ: Decreased metalloproteinase production as a response to mechanical pressure in human cartilage: a mechanism for homeostatic regulation. Arthritis Res Ther 2006, 8:R149.

34. Gibson JS, Milner PI, White R, Fairfax TP, Wilkins RJ: Oxygen and reactive oxygen species in articular cartilage: modulators of ionic homeostasis. Pflugers Arch 2008, 455:563-573.

35. Murphy CL, Sambanis A: Effect of oxygen tension and alginate encapsulation on restoration of the differentiated phenotype of passaged chondrocytes. Tissue Eng 2001, 7:791-803.

36. Murphy CL, Polak JM: Control of human articular chondrocyte differentiation by reduced oxygen tension. J Cell Physiol 2004, 199:451-459.

37. Adesida AB, Grady LM, Khan WS, Hardingham TE: The matrixforming phenotype of cultured human meniscus cells is enhanced after culture with fibroblast growth factor 2 and is further stimulated by hypoxia. Arthritis Res Ther 2006, 8:R61.

38. Robins JC, Akeno N, Mukherjee A, Dalal RR, Aronow BJ, Koopman P, Clemens TL: Hypoxia induces chondrocyte-specific gene expression in mesenchymal cells in association with transcriptional activation of Sox9. Bone 2005, 37:313322.

39. Amarilio R, Viukov SV, Sharir A, Eshkar-Oren I, Johnson RS, Zelzer E: HIF1alpha regulation of Sox9 is necessary to maintain differentiation of hypoxic prechondrogenic cells during early skeletogenesis. Development 2007, 134:3917-3928.

40. De Ugarte DA, Morizono K, Elbarbary A, Alfonso Z, Zuk PA, Zhu M, Dragoo JL, Ashjian P, Thomas B, Benhaim P, Chen I, Fraser J, Hedrick $\mathrm{MH}$ : Comparison of multi-lineage cells from human adipose tissue and bone marrow. Cells Tissues Organs 2003, 174:101-109.
41. Kuznetsoy SA Mankani MH, Gronthos S, Satomura K, Bianco P Robey PG: Circulating skeletal stem cells. J Cell Biol 2001, 153:1133-1140.

42. De Bari C, Dell'Accio F, Tylzanowski P, Luyten FP: Multipotent mesenchymal stem cells from adult human synovial membrane. Arthritis Rheum 2001, 44:1928-1942.

43. Murphy JM, Fink DJ, Hunziker EB, Barry FP: Stem cell therapy in a caprine model of osteoarthritis. Arthritis Rheum 2003, 48: 3464-3474.

44. Ponticiello MS, Schinagl RM, Kadiyala S, Barry FP: Gelatinbased resorbable sponge as a carrier matrix for human mesenchymal stem cells in cartilage regeneration therapy. J Biomed Mater Res 2000, 52:246-255.

45. Adachi N, Ochi M: [Regenerative medicine for rheumatoid arthritis-current status and problems]. Nippon Rinsho 2005, 63(Suppl 1):666-671.

46. Kanichai M, Ferguson D, Prendergast PJ, Campbell VA: Hypoxia promotes chondrogenesis in rat mesenchymal stem cells: a role for AKT and hypoxia-inducible factor (HIF)-1alpha. J Cell Physiol 2008, 216:708-715.

47. Lennon DP, Edmison JM, Caplan Al: Cultivation of rat marrowderived mesenchymal stem cells in reduced oxygen tension: effects on in vitro and in vivo osteochondrogenesis. J Cell Physiol 2001, 187:345-355.

48. Mueller MB, Tuan RS: Functional characterization of hypertrophy in chondrogenesis of human mesenchymal stem cells. Arthritis Rheum 2008, 58:1377-1388.

49. de Crombrugghe B, Lefebvre V, Nakashima K: Regulatory mechanisms in the pathways of cartilage and bone formation. Curr Opin Cell Biol 2001, 13:721-727.

50. Khan WS, Adesida AB, Hardingham TE: Hypoxic conditions increase hypoxia-inducible transcription factor 2alpha and enhance chondrogenesis in stem cells from the infrapatellar fat pad of osteoarthritis patients. Arthritis Res Ther 2007, 9:R55.

51. Jaakkola P, Mole DR, Tian YM, Wilson Ml, Gielbert J, Gaskell SJ Kriegsheim Av, Hebestreit HF, Mukherji M, Schofield CJ, Maxwell $\mathrm{PH}$, Pugh CW, Ratcliffe PJ: Targeting of HIF-alpha to the von Hippel-Lindau ubiquitylation complex by O2-regulated prolyl hydroxylation. Science 2001, 292:468-472.

52. Appelhoff RJ, Tian YM, Raval RR, Turley H, Harris AL, Pugh CW, Ratcliffe PJ, Gleadle JM: Differential function of the prolyl hydroxylases PHD1, PHD2, and PHD3 in the regulation of hypoxia-inducible factor. J Biol Chem 2004, 279:3845838465

53. Mahon PC, Hirota K, Semenza GL: FIH-1: a novel protein that interacts with HIF-1alpha and VHL to mediate repression of HIF-1 transcriptional activity. Genes Dev 2001, 15:2675-2686.

54. Lando D, Peet DJ, Gorman JJ, Whelan DA, Whitelaw ML, Bruick RK: FIH-1 is an asparaginyl hydroxylase enzyme that regulates the transcriptional activity of hypoxia-inducible factor. Genes Dev 2002, 16:1466-1471.

55. Harwood R, Grant ME, Jackson DS: Collagen biosynthesis. Characterization of subcellular fractions from embyonic chick fibroblasts and the intracellular localization of protocollagen prolyl and protocollagen lysyl hydroxylases. Biochem J 1974 , 144:123-130.

56. Hofbauer KH, Gess B, Lohaus C, Meyer HE, Katschinski D, Kurtz A: Oxygen tension regulates the expression of a group of procollagen hydroxylases. Eur J Biochem 2003, 270:4515-4522.

57. Terkhorn SP, Bohensky J, Shapiro IM, Koyama E, Srinivas V: Expression of HIF prolyl hydroxylase isozymes in growth plate chondrocytes: relationship between maturation and apoptotic sensitivity. J Cell Physio/ 2007, 210:257-265.

58. Berra E, Benizri E, Ginouves A, Volmat V, Roux D, Pouyssegur J: HIF prolyl-hydroxylase 2 is the key oxygen sensor setting low steady-state levels of HIF-1alpha in normoxia. EMBO J 2003 22:4082-4090.

59. Fang J, Yan L, Shing Y, Moses MA: HIF-1alpha-mediated upregulation of vascular endothelial growth factor, independent of basic fibroblast growth factor, is important in the switch to the angiogenic phenotype during early tumorigenesis. Cancer Res 2001, 61:5731-5735.

60. Zhang W, Petrovic JM, Callaghan D, Jones A, Cui H, Howlett C, Stanimirovic D: Evidence that hypoxia-inducible factor-1 (HIF-1) mediates transcriptional activation of interleukin-1 beta (IL-1beta) in astrocyte cultures. J Neuroimmunol 2006, 174:63-73. 